\title{
Interference of Technology in the Fine Art Market
}

\author{
Corina Dimitriu ${ }^{1}$ \\ Gheorghe Hurduzeu ${ }^{2}$
}

Abstract

Art and technology. Most of us when we are thinking of fine art we are thinking of the paintings and sculptures and we are less inclined to associate the art with technology. Yet, there are many developments in this area and technology intersects the fine art industry in different points and takes different shapes. The purpose of the paper is to identify where technology is interfering in the fine art industry.

Keywords: art market, art and technology, art transactions, art and blockchain

JEL Classification: Z11

DOI: $10.24818 / \mathrm{REJ} / 2021 / 79 / 04$

\section{Introduction}

The article is part of a larger research, which is focused on analysing the Romanian fine art market, as a player on the global market. During the research we have noted there were areas where the technology played an important role and changed the traditional ways of doing things. The paper focuses on identifying how the technology is shaping the fine art industry and if there are any externalities created.

\section{Problem Statement}

Our focus was to identify how and where technology intersects with the art market, and what changes were brought to the market. Our review started with the literature review and continued with the available online articles published by specialized art specialists. 'Performing Arts - The Economic Dilemma' by Baumol and Bowen, published in 1968 is the first serious economic study focused on performative arts and touching the fine arts. Baumol and Bowen (1968) analysis discovered 'the cost disease' and 'productive gap' concepts, which played an important role in understanding the particularities of this market. In '70, Mark

\footnotetext{
${ }^{1}$ The Bucharest University of Economic Studies, Bucharest, Romania, corina.dimitriu@gmail.com 2 The Bucharest University of Economic Studies, Bucharest, Romania, gheorghe.hurduzeu@rei.ase.to Year XXIV no. 79 March 2021
} 
Blaug has issued The Economic of the Arts and William Hendon and his colleagues founded The Journal for Cultural Economics at the University of Akron, which subsequently transformed into international biennale conference (Edinburgh). In '90, in the Journal of Economic Literature, David Thorsby and Glen Withers published The Economics of the Performing Arts. In 2006, Victor A. Ginsburgh and David Throsby published Handbook of the economics of the arts and culture, one of the most extensive materials, collecting articles centred around the art economics. Starting 2000, the economic literature expanded; in 2011 Ruth Towse published A Handbook of Cultural Economics, Iain Robertson and Derrick Chong published Understanding International Art Markets and Management in 2005 and many others started to analyze different aspects of the art market. Auction houses, and the specialized art dedicated platforms started to publish relevant articles regarding the art market results; there are annual detailed analyses - "Art Basel \&UBS Report", performed by dr. Clare McAndrew, founder of Arts Economics; ArtTactic (Art Market Research \& Analysis for The Art World) performs analysis of the auction results, publishing regularly reports regarding the economic results of the art market. Deloitte is publishing yearly the report Deloitte Art \& Finance, containing analysis related to the state of the art, the general trends, art as an investment and other matters like risk and regulations. In the last two decades, the literature around the art and cultural economics increased with the market, showing the raised interests in this area.

\section{Research Questions/Aims of the research}

The purpose of the research was to see where and how the act interacts with technology, considering the positive externalities art brings to the people.

\section{Research Methods}

The methodology used is collecting data from multiple sources and online financial reports to highlight and understand the changes done in the last three years before COVID. The research started considering the following trends in the technology: data analytics, blockchain, drones and AI. Sources include mainly online articles and surveys, podcasts and interviews with people from cultural domain, art and humanities literature, subject-specialist books as well as financial information with the purpose to identify intersections of art and technology.

Year XXIV no. 79

March 2021 


\section{Findings}

Although started a bit later than the other industries, the fine art market did not escape from being shaped by technology. COVID has put a pressure on many galleries and cultural institutions to adopt earlier digitalization to be closer to the audiences and to the public. The technology is also designing new supply chains or changes the traditional way the artwork used to be sold, valued or certified for origin. The role of the art changes, the technology and design can shape the environment around us; art and technology can help shaping the communities.

\subsection{The economic art act and externalities of the artwork}

If we are thinking at the traditional way of trading, there were few sellers, few buyers willing to exchange money for a work of art. The demand and the supply being influenced by different factors, such as the budget and the taste of the consumer, taste could be changed and refined through education. Initially we had frescoes as main artist's creation, fresco for which, later in the history, the painters were paid separately, depending on their talent. This is the main reason for which we can admire the frescoes in Italy, Venice, Millan, Florence, since Medici family or another rich person promoted and encouraged art. The outcome was on the walls and it could not be changed. The money paid to the artist was for a specific, unique art which could not be moved or transferred to another place. Looking from the economic point of view, the beneficiary - usually the church - paid for materials, at the cost of that period, and commissioned the artists, and artist hired other apprentices to help him. The cost will comprise from materials, cost for the artist and the cost with the artist's accommodation and meals (if the case). Coming back to the economic aspect (Howard, Britannica, 2017), the transactions were fairly simple and with a specific theme, involving simple terms. The economic externalities of the fresco at that time were that people visiting the church could admire the paintings, the church would benefit through the message the painting will communicate. Another benefit would be for other painters from other regions who could come and admire the church, copying the painting, but not making a perfect copy. It was inspirational and inspired and stimulated the intellect. The frescoes were also wanted in the king's castles and palaces; the transaction was similar to those described above.

In time, painters started to paint on canvas, to discover more pigments and techniques. It was fashionable among the rich people to have the portraits drawn by a painter and exposed in their house; it was a sign of wealth. The main economic value in this case is brought mainly to the owner and gives the owner a

Year XXIV no. 79

March 2021 
statute, increased more respect, bringing to the family better deals. The economic externalities are not so obvious in this case, and they are identified for this period only when the artworks were brought to museums or the castle itself was transformed into a museum.

There was a long period when the canvas was the main support for the painters. When the photography was discovered, suddenly the role of the artist has changed, from being a witness of their contemporary period and surprise the reality. The discovery of the photography changed the role and the perception of the paintings in the eyes of the public. Suddenly the reality could be copied, and people didn't need any more realistic landscape or portraits, but painting started to represent the human mind or a manifest of the social political life. Freud's unconscious has generated an entire movement in the XX century with surrealism, Salvador Dali being one of the actors in this movement. The central element is that the art has a message, the painter wanted to transmit something to the world, and this not necessarily by copying nature, but creating new patterns and with different perspectives and artwork (see Mark Rothko, Barnett Newman or all the modern and contemporary painters).

Further, in the modern times, different categories of the arts were mixed, and they have been transformed. We are assisting to visual arts, performative arts, where we can see combination of contemporary dance, music, lights; creating a unique experience for spectators; the art outcome of the show are consumed during the show. It is more like theater or contemporary dance. In this case we have no other value than the show. There is no tangible externality attached, the pleasure of assisting to the show is the privilege of those present. One externality might be determined as being the publicity the attender will gain through social media, people who did not attend the show being able to watch in the media, through the official channels or through the posts made on social networks by the spectators. However, this might be possible only where recording and using the phone is allowed.

The above was analyzed from the economic transaction point of view; analyzed from the time of sale, the art market has two sub-markets: primary market where the initial sale of an artwork takes place and the secondary market, where subsequent sales of the artworks take place. The main players on the primary market are the artists, dealers, and galleries, while on the second market the auction houses are the main players. There is a hybrid market that appeared, the online auction sites that bring together new and old works for sale, being a combination of the first and second sub-market of the art market.

Year XXIV no. 79

March 2021 


\section{Interference of the technology in the art}

As mentioned above, the artist has evolved from the traditional painting to digital painting using different apps available in our days, and furthermore to the virtual or augmented reality. The compensation for the artistic act is far from the pure barter of art and money that used to be initially. In our days, we identify cases where artists and friends of the art voluntarily contribute pro-bono to a project, having the satisfaction of making something for the society and future generations. There are cases when they are sponsored from different funds (e.g., Fine Art Unions or Cultural Institute or other institutions), or we have shows and digital art experiences in the form of projects sponsored mainly by corporations with advertising purposes. The European Union has dedicated funds for projects sustaining Creative Europe. All of these are related to the art act and the way it interacts with people. The art has evolved with the society shaping the world and being shaped by new technological developments. Below we are enumerating some of the main trends and innovations in the fine art world:

\section{A. Online Presence}

The online presence increased significantly in the last decade, generating new ways of selling the artworks. Starting from artists being present on social media, having the option to sell directly online, there are different forms or hybrid platforms that aggregate the artists pool, galleries dealers, to offer a wide and diverse collection of artworks.

In 2019, global sales in the online art and antiques market continued to be stable reaching an estimated total of $\$ 5.9$ billion, representing $9 \%$ of the value of global sales of art and antiques (Art Basel, 2019), as shown in the Figure 1.

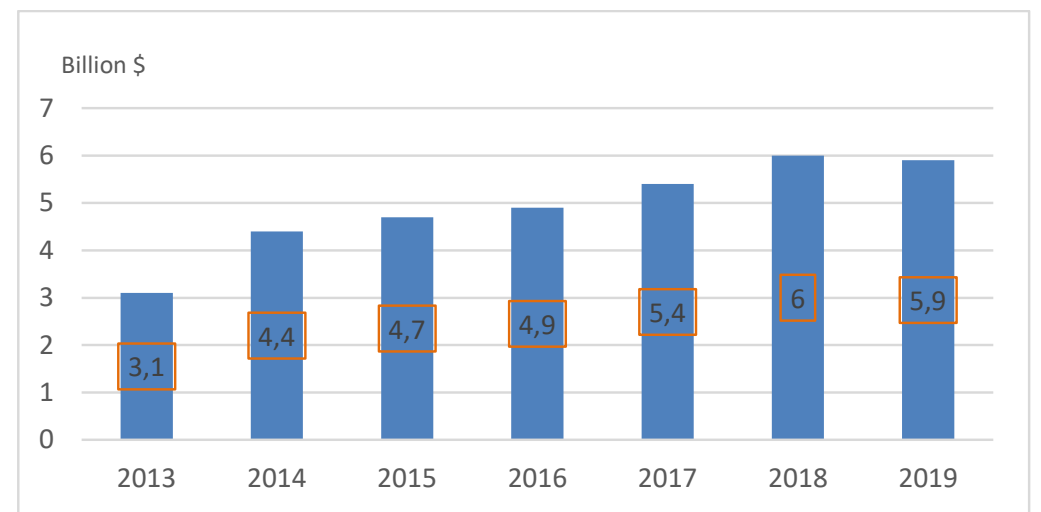

Figure 1. The online Art and Antiques Market, 2013 - 2019

Source: Arts Economics (2019)

Year XXIV no. 79

March 2021 
This share is slightly lower than the global online retail sector, where e-commerce represented $12 \%$ of total retail sales in 2018 and is expected to reach $18 \%$ by 2021 . While maintaining a steady and positive rate of growth in most years, the pace of sales of art online has grown at a slower rate than general retail e-commerce, which advanced 23\% year-on-year, to a high of $\$ 2.8$ trillion in 2018, and is expected to reach close to $\$ 4.9$ trillion in the next three years (Art Basel, 2019).

Due to the pandemic, the online sales increased in the first half of 2020, however not at the level of decrease in the traditional sales, which was higher (Art Basel, 2019).

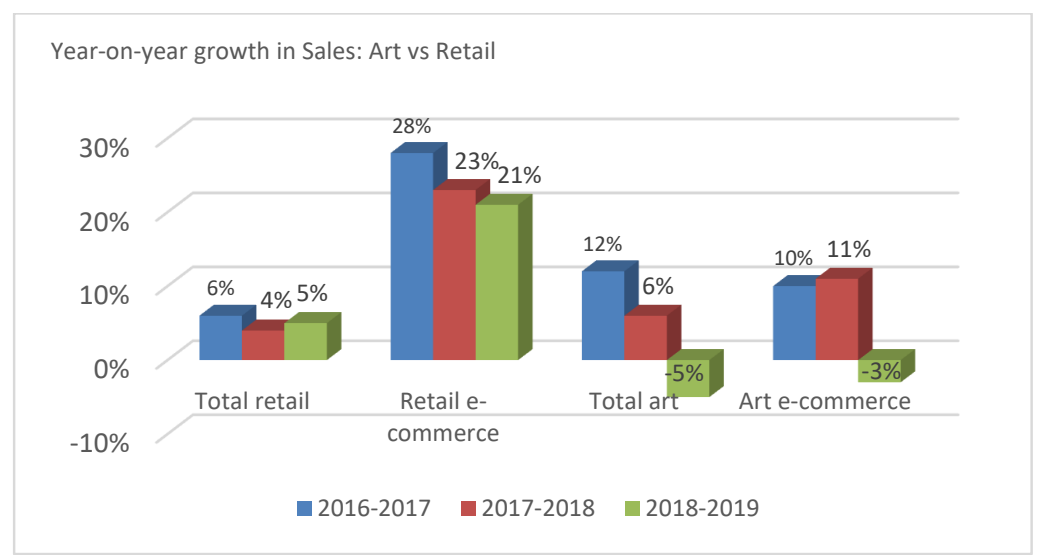

Figure 2. Online sales in the art market vs General Retail Source: Art Economics (2019) with data from eMarketer.com

The Art Basel and UBS Global Market Report (Art Basel 2019) identify two main categories with few main subcategories of online players:

a) Galleries, artists, and retail category:

i) 'Retail category' is represented by platforms which have mainly online presence, focused on art works, having usually online curators who help the buyer to identify the works he/she might like; the main players on these categories are saatchiart.com, art.com, yellowkorner.com, theartstack.com.

ii) 'third-party retail market' place is represented by the large platforms such as amazon.com, ebay.com, etsy.com. In this case the platform is offering to the seller the possibility to enroll in the marketplace and to sell to its large customer base their artworks. 
b) Auctions:

i) 'bricks and clicks' being represented by established, famous auction houses which give the possibility to its collectors to bid online during their sale. The house has a special software, and the buyer connects to the platform, bidding in real time, like the phone participation at the bid. The main global players in this category are christies.com, sothebys.com, bonhams.com, dorotheum.com, phillips.com, lauritz.com.

ii) 'online only' category is represented by the platforms which have only online presence, organizing auctions online and announcing their subscribers via email, the most representative ones being: artnet.com, artprice.com, ebth.com, auctionzip.com, lavacow.com.

iii) 'third party platforms' are the platforms where different galleries, dealers, artists are connected, together being the offer of the platform for the potential buyers. The sale may take the form of the auction or direct sale. The main platforms representing this category are: artsy.net, auctionzip.com, liveauctioneers.com, the-saleroom.com, invaluable.com, auction.fr.

From the above categories, the highest global rankings for art-specific sites, considering the number of visitors per month, were achieved by Artnet and Artsy, both with close to 4 million visitors per month.

The overall economic impact is shown by the increased presence of the online sales in the global market and the new ways of connecting multiple players on one platform offering a large a diverse portfolio of art works.

\section{B. Art with Artificial Intelligence (AI)}

In June 2017, the paper CAN: Creative Adversarial Networks Generating "Art" by Learning about Styles and Deviating from Style Norms, has been issued (Elgammal et al. 2017). The scientists proposed a new system for generating art. They built over Generative Adversarial Networks (GAN), which have shown the ability to learn how to generate novel images simulating a given distribution. They argue that such networks are limited in their ability to generate creative products in their original design, and therefore they proposed modifications to its objective to make it capable of generating creative art by maximizing deviation from established styles and minimizing deviation from art distribution. They conducted experiments to compare the response of human subjects to the generated art with their response to art created by artists. The results show that human subjects could not distinguish art generated by the proposed system from art generated by contemporary artists and shown in top art fairs. 
Portrait of Edmond Belamy was sold by Christie's for $\$ 432,000$ in October 2018 . The portrait was created by Obvious, a Paris-based art collective, using an artificial intelligence program. The artwork was produced using an algorithm and a data set of 15,000 portraits painted between the 14 th and 20th centuries (BBC, 2018). The economic impact of this AI artwork is immediate and has been proved by the fact that the piece was estimated by Christies at $\$ 7,000-\$ 12,000$ and has been sold much higher. For this piece of work, the value is given, first of all, by the uniqueness of the work, the fact that it is the first AI artwork sold at an auction house, and the value attached as heritage and witness for the times we are living. How future AI art works will be priced it will depend on their utility and potential of investment perceived by the people willing to invest in such pieces of art. The price will be influenced by the quality of the work, by the taste of the buyers and the utility people will see in the respective work.

\section{Art and blockchain valuation}

Blockchain is the technology that helps proving the origin of the artwork and keeps track of the sellers and buyers over the life of the artwork. There are few startups which focusing on using this technology to build such products. Verisart was the first company to apply blockchain technology to the physical art and collectibles market, they are also working with some of the world's best-known artists, to certify their works of art. In 2018, Verisart won the "Hottest Blockchain DApp" award at The Europas, the European tech startup awards (Butcher 2019). The origin of the artwork will help increase trust in the art market; valuation being a barrier on this market.

\section{New art investment platforms}

Traditionally the investment in art had been done by acquiring directly from the art dealers or auction houses, or by using wealth managers, investment funds, who helped the collectors or investors to diversify their portfolio and buy different pieces of art. The new technologies have created new possibilities for investing in the art market. We see new business models which have started as fundament from the traditional ones and which evolved and offer different ways of financing.

- MAecenas is a new company "the first open blockchain platform that democratises access to fine art", with the goal to create the most trusted art investment in the world. The lack of transparency, the lack of monetary resources due to high investments required, are barriers for entering on this market for many investors, as stated on its websites, MAecenas want to provide access to more investors in this market by creating a new asset class. Created on blockchain technology, the company created a tokenization process and its sells shares in the artworks that can be traded on their platform. The Company 
is still at its beginning, but it is confident on the impact will have on the market. (Maecenas, 2019)

- In 2017, a Swiss crowdfunding website, Qoqa had a round of collecting funds from its visitors to purchase a Picasso painting, Le Buste du Mousquetaire (1968). After three or four months of promotion and careful campaign, the funds were collected and the work was acquired. The Museum of Modern and Contemporary Art in Geneva was the first institution to publicly display the painting, financed in this way (Deslauriers, 2018).

Nowadays, there are multiple sites for crowdfunding where the artists can post their project online and get finance from the communities. (e.g. artistshare.com, kickstarter, IndieGoGo, PledgeMusic).

E. Google Arts \& Culture (Waters 2011) is an online platform and application developed by Google where public can access high-resolution images of artworks housed in the initiative's partner museums. Started initially with 17 museums, among which were Tate Gallery, London; the Metropolitan Museum of Art, New York City; and the Uffizi, Florence, it now comprises museums around the world, democratizing and demonetizing access in museums through the platform, using virtual tours of museums. The economic value consists in the positive economic externality created by giving access to a wide range of public who might not have the possibility to travel and visit the museum, to admire the art works in different corners of the world. The 3D and augmented and virtual reality is going to change even further such experience.

F. The use of drones for creating arts opens a wide range of possibilities; the drones can be used by an artist to create a piece of artwork as such, or to redesign the city landscapes and homes.

- KATSU is a new media artist working in New York. He works with technology, vandalism, and includes commentary on commercialism, privacy and digital culture. As a result, his work includes traditional graffiti, digital media, and conceptual artwork (Wikipedia.org 2019). Drone graffiti is not easy to do due to the precision required. He is one of the first people to ever do drone graffiti, and he achieved an amazing level of precision, enough to follow a long time fantasy of "sending my drones out my bedroom window, having them render my tags all over the city and then flying back home to me, like, in my bed." as he told Vice in a 2014 interview.

- In July 2019, the Turin based architect and design studio Carlo Ratti Associati's Paint by Drone project have come to life in the crowdsourced 
format of UFO-Urban Flying Opera. "The city is an open canvas, where people can inscribe their stories in many ways," says Professor Carlo Ratti: "Such processes have always been happening; however, with UFO Urban Flying Opera we tried to accelerate them, using drone technology to allow for a new use of painting as a means of expression." (Tumblr.com 2019)

- The ICARUS ONE is a hardware and software that allows artists to use spray enamel with the reach and scale of a drone. It is considered the The World's First Open-Source Paint (IcarusOne.com, 2018)

- In September 2017, Misha Most (2017), a Russion artist, had exhibited the first panel made by a drone only "Evolution 2.1 in Moscow showing how the artist can have a drone as an assistant. The idea of the artist was put into practice with the help of a specialized company, Interactive Lab which develops applications for games using a wide range of technology, including VR and AR. The technology company developed solutions in VR for galleries, real estate (Interactive lab 2018).

- In May 2019, Disney Enterprise has applied for a patent for drone-based painting system (see Patent application, (United States Patent and Trademark Office 2019), "a painting system that make use of drones such as modified quadrotors. The drones include a support arm that carries a paint nozzle configured for pan and tilt motion. A power supply line is connected from an external power supply to the drone to allow extended flight time. The drone has onboard controller, so painting is autonomous with no human input being required"

- ÆTERNITY'S blockchain and drone technology raises the value of urban art. Together with Voliro, Æternity works together for The Graffiti Drone project. The drone graffiti project based in Mexico City plans to combine the crowdsourcing and archival mechanisms of blockchain technology with the programmable artistic of graffiti made with drones (Dronegraffiti.com 2019). A blockchain data structure can carry and share digital objects, like images, code and instructions. Connected to programmable drones worldwide, this technology can, not only be used to paint the same painting multiple places at the same time, but also to paint the same image across time. The Public showcase of progress was shown in February 8 - 10, 2019 during Mexico City Art Week, enabling three selected artists to simultaneously create urban art on city walls and on the blockchain.

How all of these interfere with the economic aspects of our lives. First, the redesigning of the cities landscapes it's an externality brought by applying this type of art in the city. The economic externality can be either positive 
or negative, depending on everyone's perceptions. The project itself, in our days is usually financed by a private or public organization, bearing the costs and the benefits of creating such art in the city. The possibility of redesigning the city landscapes translates economically thus:

- decrease of salaries and the risk for the persons which were previously involved in painting the walls, lower number of persons will be involved in this activity if such drones start to be used.

- decrease of the metal scaffolding used to reach the walls. While this will decrease in the time, for the time being this decrease will not be significant since the drone is only painting, no repairs of the walls are carried.

- decrease of the amount of time required to finalize the painting of the wall.

The above is compensated by the increase in costs in energy spent with the drone's battery; the painting material used for painting; it might require more painting materials. The entire economic effect is still at the analysis phase.

\section{Conclusion}

The technology changes everything around us, including the art market. There are new business models, new source of funds such as crowdfunding platforms, new ways of connecting the artists, new ways of selling the artworks. The economic aspects of the art and technology is still changing, and the effects can be seen in the way public policies are being changed to include creativity and arts on the primary agenda. Drone augmented or virtual reality are going to reshape the landscape and our personal experience. Furthermore, the economic model will be changed, and the experience will be priced differently. COVID will put a pressure on the sector to reinvent itself. The central question is still to be analyzed: is the art today a memory of tomorrow, like murals used to be in Renaissance and how they are now, considering the experiences gained through technology?

\section{References}

Ahmed Elgammal, Bingchen Liu, Mohamed Elhoseiny, Marian Mazzone, The Art \& AI Laboratory - Rutgers University, Department of Computer Science, Rutgers University, NJ, USA, Facebook AI Research, CA, USA, Department of Art History, College of Charleston, SC, USA (2017). CAN: Creative Adversarial Networks Generating "Art" by Learning about Styles and Deviating from Style Norms [online]. Available at: https://arxiv.org/pdf/1706.07068.pdf [Accessed 5 Apr. 2019] 
Arora, P. and F. Vermeylen (2013), 'The end of the art connoisseur? Experts and knowledge production in the visual arts in the digital age', Information, Communication \& Society, [online]. Available at: https://www.tandfonline. com/doi/abs/10.1080/1369118X.2012.687392 [Accessed 3 Oct 2019]

Art Basel (2019). The Art Basel and UBS Global Art Market Report 2019 [online]. Available at: https://www.artbasel.com/news/art-market-report [Accessed 8 November 2019]

O. and K. Graddy (2003), 'Auctions and the price of art', Journal of Economic Literature, Vol. XLI (September 2003) pp. 763-786 [online]. Available at: http://citeseerx.ist.psu.edu/viewdoc/download?doi=10.1.1.660.8846\&rep $=$ rep1\&type $=$ pdf $[$ Accessed 3 Oct 2019]

Baumol, W. (1986), 'Unnatural value: Or art investment as floating crap game', American Economic Review, vol 76, No2 Papers and Proceedings of the NinetyEighth Annual Meeting of the American Economic Association (May, 1986), pp. 10-14. [online]. Available at: https://artmarketbaruch.files. wordpress.com/2012/04/floatingcrapgame.pdf [Accessed 4 Oct 2019]

BBC (2018) Portrait by AI program sells for $\$ 432,000$ [online]. Available at: https://www.bbc.com/news/technology-45980863 [Accessed 10 Apr 2019]

Bearman, David (2000), 'Museum strategies for success on the Internet', in Giskin Day (ed.), Museum collections and the information highway. Proceedings of a Conference on Museums and the Internet, London: Science Museum

Ben Davis (2011) Hype and Hyperreality: Zooming in on Google Art Project, [online]. Available at: http://www.artinfo.com/news/story/36950/hypeandhyperreality-zooming-inon-google-art-project/?page $=2$ [Accessed 8 Oct 2019]

Deloitte (2019). Art \& Finance Report, [online]. Available at: https://www2.deloitte.com/lu/en/pages/art-finance/articles/art-financereport.html [Accessed 8 July 2019].

Dronegraffiti.com (2019). [online]. Available at: https://www.dronegraffiti.com/ [Accessed 20 Feb 2019]

Ginsburgh, V., Mei, J. and Moses, M. (2006), 'The computation of price indices', in Victor Ginsburgh and David Throsby (eds.), Handbook of the Economics of Art and Culture, Amsterdam: North-Holland

Helene Deslauriers (2018) Crowdfunding allows Swiss to retain a Picasso [online]. Available at: https://ial.uk.com/crowdfunding-allows-swiss-to-retain-apicasso/ [Accessed 10 Oct 2019]

IcarusOne.com (2018). [online]. Available at: http://www.icarusone.com [Accessed 10 Nov 2019]

Interactive lab (2018). [online]. Available at: http://www.interactivelab.ru/

Year XXIV no. 79

March 2021 
Jeremy R. Howard (2017) Art Market, [online]. Available at: https://www.britannica.com/topic/art-market [Accessed 6 July 2019].

Maecenas.co (2019). [online] Available at https://www.maecenas.co/ [Accessed 10 Oct 2019]

Marty, P.F. (2007), 'The changing nature of information work in museums', Journal of the American Society for Information Science and Technology

Butcher, M. (2019) Art on Blockchain pioneer Verisart raises $\$ 2.5 \mathrm{M}$ for art and collectibles certification [online]. Available at: https://techcrunch.com/ 2019/10/03/art-on-blockchain-pioneer-verisart-raises-2-5m-for-art-andcollectibles-certification/ [Accessed 7 Nov 2019]

Most, M. (2017) Evolution 2.1 - artist drone [online]. Available at: http://www.mishamost.com/exhibitions-1/2017/10/10/evolution21 [Accessed 10 Nov 2019]

Tumblr.com (2019). [online]. Available at: https://dronegraffiti.tumblr.com/ [Accessed 10 Dec 2019]

United States Patent and Trademark Office (2019) Website. Page US20190127064. [online]. Available at: http://pdfaiw.uspto.gov/.aiw?docid=20190127064 \&SectionNum=1\&IDKey=8324A06B21FB\&HomeUrl=http:/ /appft.uspt o.gov/netacgi/nph-Parser?Sect1 $=$ PTO1\%2526Sect $2=$ HITOFF $\% 2526 \mathrm{~d}=$ PG01\%2526p $=1 \% 2526 \mathrm{u}=\% 25252 \mathrm{Fnetahtml} \% 25252 \mathrm{FPTO} \% 25252 \mathrm{Fsrch} n$ um.html $\% 2526 \mathrm{r}=1 \% 2526 \mathrm{f}=\mathrm{G} \% 2526 \mathrm{l}=50 \% 2526 \mathrm{~s} 1=\% 2525222019012706$ 4\%252522.PGNR.\%2526OS=DN/20190127064\%2526RS=DN/2019012 7064 [Accessed 10 Nov 2019]

Waters, Florence (2011). The best online culture archives. The Telegraph. [online] Available at https://www.telegraph.co.uk/culture/8296365/The-bestonline-culture-archives.html [Accessed 2 February 2011]. 